\title{
Imperatives in Past Online Discussions: Another Helpful Source for Community Newcomers?
}

\author{
Lu Xiao \\ Syracuse University, U.S.A. \\ Syracuse, NY, U.S.A. \\ lxiao04@syr.edu
}

\author{
Jeffrey V. Nickerson \\ Stevens Institute of Technology \\ Hoboken, NJ, U.S.A \\ jnickerson@stevens.edu
}

\begin{abstract}
Experienced members of online communities use discussion to familiarize newcomers with norms. These members use imperatives, a kind of directive speech act, to suggest a course of action. A method for automatically recognizing such imperatives is described here. The recognition performance of the algorithm is compared to that of human readers. In addition, to test and illustrate the technique, the imperatives in a sample of Wikipedia deletion discussions are extracted, analyzed, and discussed. The method may be used not only to understand a community's culture and practices but also to elicit information that is beneficial to the community's newcomers.
\end{abstract}

\section{Introduction}

The retention of newcomers is decreasing in open source communities $[18,49]$. It may be that as communities evolve, they create barriers to entry [19]. One such barrier is the cumulated community norms and practices. While experienced members are familiar with them, new members may find it challenging to absorb and apply them. Typically, newcomers of a community of practice learn norms and practices by participating in the community's activities, and in particular by observing and interacting with members that are more experienced. While learning by observing is common in real world activities [38], it can be problematic in online communities because of the lack of face-to-face interaction. It is especially challenging for newcomers who may not be able to identify easily who the experienced members are.

On the other hand, the more experienced members offer advice in order to help newcomers behave properly, and these suggestions are often available in the communication record in the online environment. Therefore, one approach to address the barrier of community's continued productivity is to extract information about these suggestions from the communication record and present it to newcomers to accelerate their learning.

We explored the potential of this approach in the context of Wikipedia community, focusing on its Article for Deletion (AfD) discussions. Wikipedia is an online community in which members strive for offering an online encyclopedia through open online collaboration. To ensure the quality of its articles, Wikipedia has established a community practice to examine and delete the articles that are not appropriate to be included. Essentially, if the inclusion of an article is doubted by the community, an online discussion called "Article for Deletion" (AfD) is hold for a period of time (often 7 - 10 days) to determine how to handle the article. During this period, any user can participate in the discussion by offering his/her opinion (e.g., to keep the article) and providing the corresponding rationale, i.e., the justification of his/her opinion. Wikipedia's AfD policy requires that the final decision about the article be made based on the rationales as opposed to the number of votes for each opinion. In general, the community has about 50 to 80 AfD discussions per day. In Wikipedia, these AfD discussions are organized according to the date the discussions were started.

An example AfD discussion page can be found by following this link:

https://en.wikipedia.org/wiki/Wikipedia:Articles_for_d eletion/Log/2017_May 20.

We analyze the AfD discussions for two reasons. First, prior studies demonstrate the necessity of understanding the community's practices in AfD discussion context. For example, Schneider, Samp, Passant, and Decker [40] found that while experienced members are familiar with Wikipedia policies and the community's practices in these deletion discussions, newcomers often do not behave properly by taking their personal emotion to discussion and being confused about the policy of deletion. Second, it has been shown that AfD discussions are rational and reflect the community's vision on encyclopedia 
articles, and experienced Wikipedians offer suggestions to each other [50]. Our preliminary analysis of AfD discussion data also shows that members do offer suggestions to others. In some cases, the suggestions take the form of polite advice; in other cases, they are so strong they can be considered direct requests. In this paper, we will use the phrase suggestions and requests to represent these related attempts to shape the behavior of the newcomers. For example, consider the following quotes from AfD discussions:

1. Add the information, and please give us some information so we can judge these sources.

2. Let's avoid compounding the BLP issues caused by the existence of this article, in violation of notability and Blp policies, by having it snowdeleted post-haste.

3. You must first discuss the matter there, and you need to be specific.

4. Perhaps time would be better spent adding more and improving the article rather than just arguing here.

5. Instead of complaining, how about finding such content and improving the article?

As shown in these examples, these suggestions and requests from AfD participants influence various aspects of the discussions: how to judge the content of the article (the first example), how to behave in discussions (the fourth example), and how to justify or argue (the third example). This implies that extracting and organizing these patterns have the potential of helping the newcomers. For example, with this extracted knowledge, one may build a Q\&A page or a recommender system based on the AfD community practices.

From the language use perspective, such suggestions and requests are often made in the form of directives. A directive is a speech act in which the speaker's intention is to get the hearer to do something [41]. The form of directives varies according to the context. As one of the six types of directives, imperatives asks or advises someone to do or not to do something [15]. In most cases, the predicate in an imperative is an action verb, and the subject is secondperson (you), and is often omitted: see the first example above. Sometimes, as in the fourth example, words of politeness and adverbial modifiers of the verb are included. This is in contrast to the more direct request illustrated by the third example.

We extracted and analyzed the imperative statements from 4,593 discussions using a computational technique described in [30]. Our hypothesis was that imperatives are likely to point to knowledge that will help newcomers understand the community's norms and practices in these discussions.
Our analysis of the extracted imperatives confirmed this hypothesis.

The remainder of the paper organized as follows. We first review the related studies on helping newcomers in online communities and specifically in Wikipedia. During the review process, we found that while various approaches have been explored to help newcomers, the potential of imperative recognition as a means to extract knowledge had not yet been investigated. After summarizing past relevant studies, we explain our research methodology. We describe our dataset, provide a brief review of the computational technique we use to extract the imperatives, and outline our content analysis process. We then present our analysis results and conclude with implications for helping online newcomers.

\section{Background}

\subsection{Helping Newcomers in the Online Communities}

The importance of attracting, sustaining, and growing the newcomer population in communities is well documented [21, 25, 26, 29, 37]. Scholars have explored the factors that affect newcomers' returning behavior, such as

- the community's replies to the newcomers' posts $[23,42]$,

- the use of socialization tactics in the communities [10],

- $\quad$ the motivational factor [8,12, 28, 33, 34, 36], and

- the norms the newcomers are expected to accept in order to be part of the community [43].

Using a machine learning approach, Burke, Joyce, Kim, Anand, and Kraut [5] analyzed about 41,000 messages from Usenet newsgroups. They identified the rhetorical strategies in the users' introduction or request posts that increased the likelihood of getting replies from the online community. Posters whose introduction or request made a reference to their lurking behavior in the community or their personal connection to the topic of discussion were more likely to get a reply. Their later analysis [6] also identified the newcomers' rhetorical strategies which could help them had better interact with the online communities.

Online communities face challenges relating to the recruitment and retention of newcomers $[8,26,28,33$, 34]. After joining the online community, newcomers spend time, intentionally or unintentionally, on learning about the norms and practices accepted by the community. Kiesler, Kraut, Resnick, and Kittur [24] suggested that there are three ways in which people learn the norms of a community: observing other community members' behaviors and their 
consequences, reading or referring to the instructive generalizations or codes of conduct (in this case, the Wikipedia policy pages), and behaving and receiving feedback directly from the community.

During this period, the community may apply various tactics to help newcomers get familiar with the community's norms [7, 16, 32]. For example, MoodBar was introduced to Wikipedia for eliciting newcomers' editing experiences. With the MoodBar, editors choose an emoticon that represents their mood at the moment (e.g., a smiley face) and submit this as their feedback along with their explanation. Morgan and his colleagues [32] designed a Teahouse support space that offers newcomer-friendly features such as monitoring new editors' activities to offer support earlier than later and providing social Q\&A to facilitate positive interactions between newcomers and experienced editors. Ciampaglia and Taraborelli [11] studied whether and how the use of MoodBar had an impact on the long-term retention of Wikipedia newcomers. Examining how MoodBar was used and by whom, the authors found out the usage of this feature was strongly correlated with the users' level of contribution. With the longitudinal usage data and the comparison to those who did not use MoodBar, the authors discovered that this feature had a positive effect on the long-term retention of the studied Wikipedia newcomers.

Besides soliciting feedback from the newcomers such as with MoodBar, making the members' normative behavior visible to the whole community is also beneficial because it helps newcomers learn. This can be accomplished by publicly displaying and contrasting appropriate and inappropriate behavior, and by publicly displaying feedback. Other researchers have suggested the use of innovative visualization techniques to help newcomers get familiar with the community context [20, 47].

\section{2. Wikipedia Discussions}

Wikipedia is considered to be one of the most successful collaborative information repositories. A large group of volunteers collaboratively participate in building and maintaining the encyclopedia, which includes the processes of creation, editing, deletion, etc. Wikipedia discussions have been studied widely from various perspectives. Wikipedia quality discussions offer a useful resource for studying information quality topics because the assessments of quality are closely connected to the artifacts being judged, and these assessments are recorded and available for analysis [44]. Geiger and Ford [17] showed that often the articles deleted because they did not fit the norms of a Wikipedia article as judged by
Wikipedians. Geiger and Ford's study discusses the importance of being familiar with the Wikipedia community's values, norms, and practices in deciding whether the discussed article should be deleted. Using the Affective Norms for English Words (ANEW), Laniado, Kaltenbrunner, Castillo, \& Morell [27] analyzed the emotions expressed by the Wikipedia editors in talk page discussions.

Different research methods have been employed to study the norms and practices in Wikipedia discussions (e.g., [13, 14, 51]). Factor analysis of word usage has been applied to Wikipedia discussions [14]. Cho, Chen, and Chung [9] surveyed 223 Wikipedians to explore people's motivation and practices in collaborative knowledge-building activities in Wikipedia context. To study the effects of anonymity on the groupthink behavior in online collective activities, Tsikerdekis [45] also used a survey method and randomly selected Wikipedians from the Englishlanguage Wikipedia community. Interested in understanding how Wikipedians manage task-related conflicts and how these conflicts affect the performance, Arazy, Yeo, and Nov [1] used a traditional manual content analysis approach to study the Wikipedia articles' talk page discussions. Xiao and Askin [50] analyzed the AfD discussion content through an open-coding process, and examined the correlation relationships between various discussion aspects, including the types of the votes, the discussion situation and the discussion outcome.

Computational techniques have been developed to analyze participants' behavior and practices in Wikipedia discussions. Alignment moves and authority claims were annotated in 365 discussions from Wikipedia talk pages [3]. The authors defined a "social act" that is "a communicative move aimed at social positioning of a discussant within a group of participants, which may be specialized dialog acts” ([3], p.48). In their work, an authority claim is a statement made by discussants in order to bolstering their credibility in the discussion. Computational techniques have been used to identify different types of authority claims in the discussions [31]. Rosenthal and McKeown [39] used a machine learning approach to detect opinionated claims in online discussions. Opinionated claims are those that come with the speaker's intention to convince others to believe or accept them. Often such claims come with rationales [4]. Their annotation results show that Wikipedia talk page discussions are rich in opinionated claims, suggesting that Wikipedia Talk Page discussions are good places to find rationales.

A speech act is a performative utterance in communication [2]. According to speech act theory, a speaker might be performing any or all of the 
following three acts when speaking: a locutionary act, an illocutionary act, and a perlocutionary act. A locutionary act is the act of uttering words, phrases or clauses that conveys literal meaning by means of a lexicon, syntax and phonology. An illocutionary act is the act of expressing the speaker's intention. A perlocutionary act is the act performed by or resulting from saying something. It is the consequence of, or the change brought about by the utterance. Here is an example that shows how these three acts are conveyed in a text. The statement "Follow the guideline" is a locutionary act by itself. The speaker's intention is to ask the listener to do something, i.e., to follow the guideline. If the listener did follow the guideline after this statement, then the perlocutionary act was successful such that speaker succeeded in persuading the listener to follow the guideline.

In speech act theory, the illocutionary act is the most central part among the three acts. Speech act theory has been utilized in an analysis of Wikipedia project discussions [35]. Our preliminary analysis of AfD discussion data also suggests that offering suggestions and advice in this context is often associated with one type of illocutionary speech act, namely, imperatives. However, we are not aware of any prior study that explored the potential of extracting these imperatives statements from the AfD discussion content to help newcomers learn about the communities' practices and norms. Our research questions are then: Through the use of imperative statements, what kind of requests or suggestions do participants make to the others in Wikipedia's AfD discussions? Do they reveal communities' practices and norms thus potentially useful to newcomers?

\section{Research methodology}

\subsection{The Imperative Detection Tool}

To understand the types of requests made in the AfD discussions in general through the participants' imperative comments, being able to extract and analyze imperatives from many discussions is necessary. We chose one week of the Wikipedia AfD discussions for each month of 2013, that is, 84 days of AfD discussion pages. This gave us 4,593 discussions in total. On the other hand, it is a daunting task to annotate manually imperatives from thousands of discussions.

For example, just one day's AfD discussions on May 2 2013, had 54 AfD discussions and over 30,000 words

(https://en.wikipedia.org/wiki/Wikipedia:Articles_for deletion/Log/2013_May_2).
To address this issue, we used a tool that automatically detects and extracts imperative statements from Wikipedia AfD discussions, described by [30]. This tool used two basic signals of an imperative: 1) the sentence has a verb (in its base form) as the root in the phrase structure and this particular verb has no subject child in the dependency structure, or 2) the personal pronoun or noun (e.g., you, they, username) is followed by a modal verb (e.g., should, must). Mao, Mercer, and Xiao [30] evaluated this technique with human annotations and achieved precision of 0.8447 and recall of 0.7337 . The F1 measure is 0.7874 . With this tool, we were able to extract 2,768 imperative statements from these 4,593 discussions.

\subsection{Data Cleaning}

We analyzed the extracted 2,768 statements from the imperative detection tool with the goal of discarding those that were either not imperatives (i.e., the false positives) or not useful for the goal of the imperative analysis. A research assistant (RA), a Master's student in Library \& Information Science, was recruited for the data analysis. At the beginning, the first author and the research assistant reviewed one day of the extracted imperatives independently and discussed their results through face-to-face meetings. The two then formalized a scheme to help filter the statements from the corpus. The RA re-analyzed the selected imperatives using this scheme and discussed the results with the first author. The two reached agreement and reviewed the rest of the corpus independently. Of the extracted 2,768 statements by the tool, the first author and the RA identified 1,291 and 1,272 imperatives respectively. The first author compared these analysis results and finalized the data set for further analysis ( $\mathrm{N}=1,272$ statements).

A closer examination of the discarded statements shows that about $6.5 \%$ of them were the ones that were incorrectly detected due to the implicit subject feature (e.g., I, it). That is, the detection algorithm finds statements where I or It has been dropped, but not all of such statements are imperatives. About $8.9 \%$ of the statements were imperative but did not contain decontextualized knowledge. Examples of such statements are Come on here, Listen, Go ahead. They are imperatives about the conversation itself rather than about plans for action that are related to editing. In addition, some of these statements are duplicates of the useful imperatives of the analysis. For example, in the AfD discussion page on July 6, 2013, the user Irānshahr offered his/her identical comment "Quote the references to show that ..." in two places in the discussions. The imperative tool extracted the sentence 
twice but in our review, the duplicate was discarded. Another example is in the AfD discussion page on July 7, 2013 - the original statement "Let's not feed the trolls and delete this" appeared again as a direct quote in another user's comment.

About $3 \%$ of the detected imperatives ( $N=84$ statements) were those that are not constructive to the process of helping newcomers. They may be insults, sarcastic or incendiary remarks and other similar sentences that were made to, seemingly, derail the discussion. Examples are:

- Use some damn common sense

- If you like Wikinews so much, go write there instead

- Please explain ...

- You explain yourself, you miscreant!!

- He's notable, do a little research before I set you up with Manti's girlfriend!

- $\quad$ Read the damn intro, Hammer.

Besides those incorrectly detected imperatives due to the existence of the implicit subject, the first author and RA identified 884 of 2,768 statements (31.9\%) as non-imperatives. So overall, the tool performed worse in the imperative recognition of the 4,593 discussions than in the evaluation task described in the previous section. We identified three reasons for this:

1. The more severe impact of parser mistakes in the larger dataset

Although this issue was noticed in the evaluation task, it was less severe given the smaller amount of discussion data. In this larger dataset, such mistakes happen more frequently, and the same mistake occurred multiple times as well. For example, the nonEnglish phrases like ISBN and Erpert, which appeared multiple times in the dataset, were incorrectly detected each time thus dropping the performance level quite significantly. In addition, automated comments in the AfD discussions tended to be detected, and these appeared multiple times. For example, the incorrectly detected comment generated by the cyberbot "Automated comment: This AfD was not correctly transcluded to the log (step 3). I have transcluded it to ..." - appeared 10, 4, 7, and 6 times in the AfD discussions of December $1^{\text {st }}, 2^{\text {nd }}, 4^{\text {th }}$, and $6^{\text {th }}$ respectively.

2. The more varied text use in the larger dataset

Although the AfD discussion participants tend to follow certain formatting practices such as offering their votes first (e.g., Keep, Delete, Redirect, ...) and then provide their rationales, this is not always the case. The larger dataset showed more variation in the writing and formatting styles than the one-day discussion in the evaluation task. In other words, the unstructured text environment made the tool more prone to error given a larger dataset.

3. The lack of function to detect a special kind of commissive act

Although the dataset examined here is not particularly large, the above two reasons already demonstrate the challenges of eliciting knowledge from a large amount of online user-generated data. The third reason is related to the function of the tool. As described in the literature review section, the commissive acts commit the speaker herself to some future course of action. Therefore, a statement like Let me be as straightforward as possible: If there are no better sources then the software is simply not notable, at least not yet is a commissive act. On the other hand, a statement like Let me know if you need more help is a request in the form of an imperative. Our tool is not able to distinguish these two situations at this stage, which results in some incorrect detection.

These issues may be useful clues for developing better techniques to extract speech acts. Recognizing speech acts with a high degree of accuracy will require techniques that go well beyond typical bag-of-words natural language processing methods.

\subsection{Data analysis}

To examine the usefulness of the imperatives in eliciting knowledge about the community's common practice that might be useful for newcomers, we further analyzed the selected 1,272 imperatives and identified five types of suggestions/requests made in the imperatives through an open and iterative coding process. Specifically, the first author and the RA analyzed a small subset of the data independently, and then discussed and identified together the types of categories. The RA next analyzed the 1,272 imperatives based on this. The first author then reviewed his analysis results and agreed on the coding of 1,106 statements (about $87 \%$ of agreement measure). In the cases where the disagreement occurred, the first author analyzed the statements a few more times until she was certain about the analysis.

\section{Results}

\subsection{What Types of Requests or Suggestions are in these Imperatives?}

Through our open and iterative coding, we identified five types of requests or suggestions in the imperatives as follows: 
1. Article Content Request/Suggestion

This type of imperatives suggest a course of action on how to treat or manage the content of the article being discussed. They are specific to the article being considered, thus not generalizable to other article for deletion cases. Examples are: 1). Go ahead and bundle that article in if you'd like, and see "Income in the United States" template at the top right-hand corner of that article for more; and 2). In cases where this may be necessary, (e.g. Nationwide opinion polling for the United States presidential election, 2012), consider using tables to enhance the readability of lengthy data lists.

2. Wikipedia Technical Request/Suggestion

Imperatives suggest Wikipedia technical actions in some situations. Wikipedia has a list of technical actions available about how to treat the article proposed to be deleted, such as how to merge it with another article, how to move it to a different place, etc. Compared to the imperatives in the above category, these imperatives' suggestions are about what to do with the support structures around the article, not its content. Example imperatives in this type are: 1). Summarize, merge, and redirect to 2012 Burgas bus bombing; and 2). Try clicking `Refresh ' after you get that error.

\section{Discussion Norm or Practice} Request/Suggestion

The imperative statements in this type are about instructing or articulating the community's behavioral norms or practices in the discussion context. Following are the example imperatives: 1). Incidentally, at the risk of being a stickler for language please note that this is not a vote but a discussion; 2). Please, only explain with arguments your point of view; 3). Please allow admins as much time as possible to review; and 4).Take it to "WP:ANI" If you have a problem with my editing patterns, there are more appropriate forums than this.

4. Reference Suggestion

This type of imperative statements refers the readers to a reference point. The reference point could be Wikipedia (Non-Policy) Content, Wikipedia policies, or information outside of the Wikipedia web site. The examples we selected for this category are: 1 ). Check the Dutch or French versions of the page and you will find them; 2). See, for example, Rabindranath Tagore and Rabindra Sangeet; 3) Please consider studying Wikipedia:Arguments to avoid in deletion discussions, especially its "Denying the antecedent" section; and 4). Please see Wikipedia:Notability (organizations_and_companies) \#Primary _criteria.

\section{Suggestions on Reasoning/Evaluation Perspectives}

This type of imperatives are those that make suggestions or requests on others' reasoning processes in the article evaluation. A common scenario in these imperatives is that a participant asks others to consider or reconsider aspects of an article other than its content when evaluating the article. She may present an alternative viewpoint or request the others to weigh an abstract concept (e.g., the background of the main editor of the article). Example imperatives in this type are: 1). Let's not forget that newspapers are a for-profit enterprise, as are the vast majority of news sources; 2). Remember, we both agreed that after cutting needless plot summary, the article would only amount to a stub; 3). Let's not pull the trigger so fast; and 4). Please provide evidence that this is the case.

It is worth noting that these categories are not necessarily mutually exclusive with respect to the other categories. For example, the statement Take it to WP:ANI If you have a problem with my editing patterns, there are more appropriate forums than this is coded as an imperative that reflects the community's practice (type 3 ) as well as one in the category 4 since it referred to a Wikipedia policy. Another example is the statement Please note that this article was a new editor's first contribution and welcome them accordingly. We considered that this statement not only suggested another way to consider/evaluate the article (type 5) but also revealed a norm in this discussion space (type 3).

Table 1 presents the analysis results.

Table 1. Types of Suggestions in the Selected Imperatives and Their Percentages

\begin{tabular}{|l|c|}
\hline \multicolumn{1}{|c|}{ Type } & $\begin{array}{c}\text { Number of } \\
\text { Imperatives } \\
\text { (Percentage) }\end{array}$ \\
\hline 1. $\begin{array}{l}\text { Article Content } \\
\text { Request/Suggestion }\end{array}$ & $196(15.4 \%)$ \\
\hline 2. $\begin{array}{l}\text { Wikipedia } \\
\text { Technical } \\
\text { Request/Suggestion }\end{array}$ & $165(13.0 \%)$ \\
\hline 3. $\begin{array}{l}\text { Discussion Norm or } \\
\text { Practice } \\
\text { Request/Suggestion }\end{array}$ & $150(11.8 \%)$ \\
\hline 4. $\begin{array}{l}\text { Reference } \\
\text { Suggestion }\end{array}$ & $364(28.6 \%)$ \\
\hline
\end{tabular}




\begin{tabular}{|c|c|}
\hline & $\begin{array}{l}\text { Referring to different } \\
\text { places Including: } \\
\text { - } \quad 156(12.3 \%) \\
\text { Wikipedia policies } \\
\text { - } 145(11.4 \%) \\
\text { Wikipedia non- } \\
\text { policy content } \\
63(5.0 \%) \text { non- } \\
\text { Wikipedia content) }\end{array}$ \\
\hline $\begin{array}{ll}\text { 5. } & \text { Suggestions on } \\
\text { Reasoning/Evaluati } \\
\text { on Perspectives }\end{array}$ & 397 (31.2\%) \\
\hline
\end{tabular}

\subsection{Are these Imperative Statements Potentially Useful to Newcomers? How?}

Newcomers in AfD discussions are often not familiar with the evaluation criteria and process, and are often also new editors of Wikipedia articles [40]. We expect that type 5 imperatives will be useful to them. Type 5 imperatives are the most common suggestions/requests in our data accounting for $31.2 \%$ of the imperatives. These imperatives often evaluate the articles at a higher level or may function as a reflection trigger in the process. Besides the examples listed in 5.1., we list a few additional examples below to illustrate this point:

- $\quad$ Please comment on notability of article

- $\quad$ Please read both articles thoroughly

- Think about this article in that context

- If some big name academic sources or news agencies start talking about this society, leave me a note and I can see about helping you turn it into an article

We see these "reflection triggers" as offering high level guidelines on how to evaluate articles and some are on how to write a Wikipedia article like the last imperative example above.

Type 3 imperatives are also useful to the newcomers. They take about $11.8 \%$ of the selected data. The examples shown above for this type reveal the practices and norms on how to phrase or pitch one's perspectives in the discussion forum. They can also be about how to format messages in this discussion forum, such as the following:

First and foremost, stick to standard message formatting, so that others can contribute without disruption

Again, if you want to comment further, use the word "comment" in bold

Make your stance in "bold text”!

Some are related to the commonly expected behavior in the AfD discussions, like:
If a particular source is relevant to two aspects, then list it under both - the second can be a short-form cite, as we already use widely

Please discuss the content, not the contributor; and Make some valid arguments before deleting massive amounts of content.

Type 4 imperatives show that Wikipedia policies were referred to frequently $(12.3 \%)$. This is consistent with previous studies. For example, Viégas, Wattenberg, Kriss, and Van Ham's study [48] shows that the Wikipedia editors support strategic planning of edits and enforcement of standard guidelines and conventions in the community. In their analysis of the Wikipedia talk page discussions, the authors classified 11 types of posts among which one was the reference to Wikipedia policies and guidelines. They found about $7.9 \%$ of the posts were references to the Wikipedia guidelines.

Often when the participants mentioned Wikipedia policies, they used them to justify their viewpoints or refute the others' argument. It may help the newcomers better orient themselves in the AfD discussions if they know which policies are usually suggested. So, one next step from an imperative extraction tool such as the one used in this study is to create a list of frequently mentioned Wikipedia policies in the extracted imperatives and make the list easily accessible in AfD discussion forum environment so newcomers may refer to it as a quick reference.

Although we expected type 2 imperatives to be very useful in helping newcomers become familiar with various technical issues of handling the articles, we found instead that these statements are mainly about merging or redirecting articles. In addition, as type 1 imperatives are suggestions specific to the individual articles, it would probably be more useful if we present them along with the pointers to the articles and their editing history as cases for newcomers to study.

In summary, our analysis of the imperative statements suggest that extracting and creating a repository of the data pointed to by these imperatives from the AfD discussions may help future newcomers discover common dos and don'ts articulated by the community, and hopefully avoid common mistakes. Even the derailing imperatives reveal the don'ts or dislikes of the community.

\section{Discussion}

Our approach contributes to the research on engaging and helping newcomers familiarize themselves with an online community's practices. We are suggesting a new direction. The existing focus has been on the design of socialization tactics in online 
communities, based on theories from the field of organizational studies [22, 46]. These studies take Lave and Wenger's [29] perspective on communities of practice (CoP), and explore ways to increase interactions between the newcomers and more experienced members. Our study suggests that leveraging the social footprints left from the previous interactions in these online environments may be productive. Specifically, it is possible to use automated tools to extract knowledge about the community norms and practices. This knowledge could then be presented to newcomers at the appropriate time.

One way of leveraging this knowledge is to run the imperative detection feature on an AfD discuss page and highlight the detected imperatives in the text. Highlighting the imperatives in the discussion text not only helps users become aware of the discussed dos and don'ts in the discussions of the day but also helps preserve and emphasize the discussion context. This design is appropriate when the user is at a specific AfD discussion page.

Another idea is to offer an imperative repository based on all the AfD discussions in the past, a database can be designed to maintain the relationship between the detected imperatives and the associated contextual data including the references to the articles, the participants and their status in the community, the discussion text, and the locations of the imperatives.

This new direction to support newcomers in online communities can be applied to contexts other than Wikipedia. In online crowd activities, often users can choose when to join and when to leave and the participation is at a much larger scale than a small group activity. These open, large, and dynamic participation characteristics make it challenging for newcomers to understand the norms of the crowd. While it is important to design interactive features to get newcomers familiar with the environment, our study suggests the potential of utilizing the social footprints in the environment by mining useful information particularly useful to newcomers from the community’s communication history.

Our study has several limitations. The performance of the imperative detection technique was promising but could be improved. In Mao, Mercer, and Xiao's evaluation [31], the authors achieved a high precision of 0.8447 in comparison to a gold standard based on one day of hand-coded AfD discussion. In our analysis, a different and larger data set was analyzed and proved more challenging. For example, in the AfD discussions on January 16 of 2013, there were 52 extracted imperatives, but only 26 were kept.

Because of this large dataset, we were not able to check the recall of the tool (we would have needed to hand code the entire corpus). Given that the tool has used a pre-defined phrase list to match the modal verb phrases for detecting this type of imperatives (e.g., You/we/I + modal verb), the larger dataset is likely to contain more phrases that were not considered in the list - thus the recall is expected to be smaller than reported by [30]. In addition, the tool only focused on detecting imperative statements. As discussed in the introduction and the related work section, the discussion participants can offer their suggestions and demands through forms of directive acts other than imperatives. Future research might improve the tool by not only increasing accuracy of imperative detection but also detecting other types of directive acts.

Another limitation relates to a lack of knowledge on the writer's background. Wikipedia is open to all Internet users. Misuse of imperative statements in a user's comments may happen if the user is a non-native English speaker or is still learning to write. We caution researchers who rely on text analytics tools in studying online phenomena to consider these issues in their research.

The lack of context detection in this imperative extraction tool is a more challenging issue. Without knowing the anticipated "hearer" of the imperative (i.e., the participant the suggestion/demand was made to), and the comment(s) that triggered the writer to write the imperative, it is easy to misinterpret the imperatives. Our earlier idea of highlighting the imperatives in the text offers one way to address this limitation. More research is needed to explore how to identify and integrate discussion context.

\section{Conclusion}

It is important to understand better whatever barriers get in the way of members' engagement and productivity in online communities. In this research, we approach this problem from the community newcomer's perspective, focusing on ways to improve their community participation experiences and help them to become expert sooner. More specifically, we explored whether and how imperative statements from the community discussions may be a source for identifying community norms and practices, and we situated our research in the Wikipedia's article for deletion (AfD) discussions. Imperatives are a particular form of speech act that strongly suggest courses of action. Because of their direct nature, they can function as indicators of salient content. Our analysis of the imperative statements in AfD discussions shows that they do reveal norms and practices in participating in these discussions and in evaluating Wikipedia articles, which is what new editors need to know to become experienced editors in this context. 


\section{Acknowledgements}

We thank Mark Borden for his research assistance. This study is partially supported by the Natural Sciences \& Engineering Research Council of Canada (Discovery) and the National Science Foundation (IIS1717473).

\section{References}

[1] Arazy, O, Yeo, L and Nov, O. Stay on the Wikipedia Task: When task-related Disagreements Slip into Personal and Procedural Conflicts. J Am Soc Inf Sci Tec, 64(8), 2013, 1634-1648.

[2] Austin, J. L. How to do things with words, volume 1955, 1975. Oxford university press.

[3] Bender,E. M., Morgan, J. T., Oxley, M., Zachry, M., Hutchinson, B., Marin, A., Zhang, B. and Ostendorf, M. Annotating social acts: authority claims and alignment moves in Wikipedia talk pages. Proc. of the Workshop on Languages in Social Media, Association for Computational Linguistics, 2011, 48-57.

[4] Biran, O., and Owen, R. Identifying justifications in written dialogs by classifying text as argumentative. Proc. of Int. Conf. on Semantic Computing, 2011, 162 - 168.

[5] Burke, M., Joyce, E., Kim, T., Anand, V. and Kraut, R. Introductions and requests: Rhetorical strategies that elicit response in online communities. Communities and Technologies, 2007, 21-39.

[6] Burke, M., Kraut, R. and Joyce, E. Membership claims and requests: Conversation-level newcomer socialization strategies in online groups. Small Gr Res 41(1), 2010, 4-40.

[7] Burke, M., Marlow, C., \& Lento, T. Feed me: motivating newcomer contribution in social network sites. Proc. of the ACM Conf. on human factors in computing systems, 2009, 945-954

[8] Cappa, F., Laut, J., Nov, O., Giustiniano, L., \& Porfiri, M. Activating social strategies: Face-to-face interaction in technology-mediated citizen science. J Environ Manage, 182, 2016, 374-384.

[9] Cho, H., Chen, M., and Chung, S. Testing an integrative theoretical model of knowledge-sharing behavior in the context of Wikipedia. J Am Soc Inf Sci Tec, 61(6), 2010, 1198-1212.

[10] Choi, B., Alexander, K., Kraut, R.E. and Levine, J.M. Socialization tactics in Wikipedia and their effects. In Proc. of the ACM Conf. on Computer supported cooperative work, 2010, 107-116.

[11] Ciampaglia, G.L. and Taraborelli, D. MoodBar: Increasing new user retention in Wikipedia through lightweight socialization. In Proc. of the ACM Conf. on Computer Supported Cooperative Work \& Social Computing,
2015, 734-742.

[12] Crowston, K. and Fagnot, I. The motivational arc of massive virtual collaboration. In Proc. of the IFIP WG 9.5 Working Conf. on Virtuality and Society: Massive Virtual Communities, 2008, 1-18.

[13] Ehmann, K., Large, A. and Beheshti, J. Collaboration in context: Comparing article evolution among subject disciplines in Wikipedia. First Monday 13, 2008, 10.

[14] Emigh, W. and Herring, S.C., 2005, Collaborative authoring on the web: A genre analysis of online encyclopedias. In Proc. of the $38^{\text {th }}$ Hawaii Int. Conf. on System Sciences, IEEE, 2005, 1 - 11.

[15] Ervin-Tripp, S. Is Sybil there? The structure of some American English directives. Lang Soc 5(1), 1976, 25-66.

[16] Farzan, R., Kraut, R., Pal, A. and Konstan, J. Socializing volunteers in an online community: a field experiment. In Proc. of the ACM Conf. on Computer Supported Cooperative Work, 2012, 325-334.

[17] Geiger, R. S. and Ford, H. Participation in Wikipedia's article deletion processes. In Proc. of the ACM $7^{\text {th }}$ Int. Sym. on Wikis and open collaboration, 2011, 201-202.

[18] Halfaker, A., Geiger, R. S., Morgan, J. T. and Riedl, J. The rise and decline of an open collaboration system: How Wikipedia's reaction to popularity is causing its decline. Am Behav Sci 57(5), 2012, 664-688.

[19] Halfaker, A., Kittur, A. and Riedl, J. Don't bite the newbies: how reverts affect the quantity and quality of Wikipedia work. In Proc. of the ACM $7^{\text {th }}$ Int. Sym. on Wikis and Open Collaboration, 2011, 163-172.

[20] Heer, J., Viégas, F. B. and Wattenberg, M. Voyagers and voyeurs: supporting asynchronous collaborative information visualization. In Proc. of the ACM SIGCHI Conf. on Human factors in computing systems, 2007, 1029-1038.

[21] Jackson, C., Østerlund, C., Maidel, V., Crowston, K. and Mugar, G. Which Way Did They Go?: Newcomer Movement Through the Zooniverse. In Proc. of the $19^{\text {th }}$ ACM Conf. on Computer-Supported Cooperative Work \& Social Computing, 2016, 624-635.

[22] Jones, G.R. Socialization tactics, self-efficacy, and newcomers' adjustments to organizations. Acad Manage $J$ 29(2), 1986, 262-279.

[23] Joyce, E. and Kraut, R.E. Predicting continued participation in newsgroups. J Comput-Mediat Comm 11(3), 2006, 723-747.

[24] Kiesler, S., Kraut, R., Resnick, P. and Kittur, A. Regulating behavior in online communities. Building Successful Online Communities: Evidence-Based Social Design, MIT Press, Cambridge, MA, 2012. 
[25] Kim, A.J. Community building on the web: Secret strategies for successful online communities. AddisonWesley Longman Publishing Co., Inc. 2000.

[26] Kraut, R.E., Burke, M., Riedl, J. and Resnick, P. The challenges of dealing with newcomers. In Kraut, R. E. \& Resnick, $P$. (eds.) Building successful online communities: Evidence-based social design, Cambridge, MA, MIT Press, 2012.

[27] Laniado, D., Kaltenbrunner, A., Castillo, C. and Morell, M.F. Emotions and dialogue in a peer-production community: the case of Wikipedia. In Proc. of the $8^{\text {th }} A C M$ Annual International Symposium on Wikis and Open Collaboration, 2012, 9.

[28] Laut, J., Cappa, F., Nov, O., \& Porfiri, M. Increasing citizen science contribution using a virtual peer. J Assoc Inf Sci Tech, 68(3), 2017, 583-593.

[29] Lave, J. and Wenger, E. Situated learning: Legitimate peripheral participation. Cambridge university press, 1991.

[30] Mao, F., Mercer, R. and Xiao, L. Extracting imperatives from wikipedia article for deletion discussions. In Proc. of the $1^{\text {st }}$ Workshop on Argumentation Mining, 2014, 106-107.

[31] Marin, A., Zhang, B. and Ostendorf, M. Detecting forum authority claims in online discussions. In Proc. of the Workshop on Languages in Social Media, Association for Computational Linguistics, 2011, 39-47.

[32] Morgan, J.T., Bouterse, S., Walls, H. and Stierch, S. Tea and sympathy: crafting positive new user experiences on wikipedia. In Proc. of the ACM Conf. on Computer supported cooperative work, 2013,839-848.

[33] Nov, O., Arazy, O., \& Anderson, D. Scientists@ Home: what drives the quantity and quality of online citizen science participation? PloS One, 9(4), 2014, e90375.

[34] Nov, O. What motivates Wikipedians? Communications of the ACM, 50 (11), 2007, 60-64.

[35] Ozturk, P. and Nickerson, J. Paths from talk to action. In Proc. of the $36^{\text {th }}$ Int. Conf. on Information Systems, 2015.

[36] Preece, J. and Shneiderman, B. The reader-to-leader framework: Motivating technology-mediated social participation. AIS Transactions on human-computer interaction 1(1), 2009, 5.

[37] Priedhorsky, R., Chen, J., Lam, S.T.K., Panciera, K., Terveen, L. and Riedl, J. Creating, destroying, and restoring value in Wikipedia. In Proc. of the ACM Int. Conf. on Supporting group work, 2007, 259-268.
[38] Rogoff, B., Paradise, R., Arauz, R.M., Correa-Chávez, M. and Angelillo, C. Firsthand learning through intent participation. Annu Rev Psychol 54(1), 2003, 175-203. [39] Rosenthal, S. and McKeown, K. Detecting opinionated claims in online discussions. In 2012 IEEE $6^{\text {th }}$ Int. Conf. on Semantic Computing, 2012, 30-37.

[40] Schneider, J., Samp, K., Passant, A. and Decker, S. Arguments about deletion: How experience improves the acceptability of arguments in ad-hoc online task groups. In Proc. of the ACM Conf. on Computer supported cooperative work, 2013, 1069-1080.

[41] Searle, J. R. A classification of illocutionary acts. Lang Soc 5(1), 1976, 1-23.

[42] Singh, V., Kathuria, S. and Johri, A. Newcomer integration and learning in OSS technical support communities. In Proc. of the ACM Conf. on Computer Supported Cooperative Work Companion, 2012, 215-218.

[43] Stommel, W. and Koole, T. The online support group as a community: A micro-analysis of the interaction with a new member. Discourse Stud 12(3), 2010, 357-378.

[44] Stvilia, B., Twidale, M.B., Smith, L.C. and Gasser, L. Information quality work organization in Wikipedia. $J \mathrm{Am}$ Soc Inf Sci Tec 59(6), 2008, 983-1001.

[45] Tsikerdekis, M. The effects of perceived anonymity and anonymity states on conformity and groupthink in online communities: A Wikipedia study. J Am Soc Inf Sci Tec 64(5), 2013, 1001-1015.

[46] Van Maanen, J.E. and Schein, E.H. Toward a theory of organizational socialization In J. Van Maanen (Ed.), Research in organizational behavior, 1 (1977).

[47] Viégas, F.B. and Smith, M. Newsgroup crowds and authorlines: Visualizing the activity of individuals in conversational cyberspaces. In Proc. of the 37th IEEE Annual Hawaii Int. Conf. on System Sciences, 2004, 10

[48] Viégas, F. B., Wattenberg, M., Kriss, J., \& Van Ham, F. Talk before you type: Coordination in Wikipedia. In Proc. of the 40th IEEE Annual Hawaii Int. Conf. on System Sciences, 2007, 78a

[49] Von Krogh, G., Spaeth, S. and Lakhani, K.R. Community, joining, and specialization in open source software innovation: a case study. Res Policy 32(7), 2003, 1217-1241.

[50] Xiao, L. and Askin, N. What influences online deliberation? A Wikipedia study. J Assoc Inf Sci Tech 65(5), 2014, 898-910.

[51] Zhu, H., Kraut, R.E. and Kittur, A. Effectiveness of shared leadership in Wikipedia. Hum factors 55(6), 2013, 1021-1043. 